\title{
Substitution of labour and energy in agriculture and options
} for growth

C. T. de Wit

Department of Theoretical Production Ecology, Agricultural University, Wageningen, the Netherlands

Accepted: 22 May 1975

\section{Summary}

Viewed from the technical angle, labour and energy may be considered the basic resources for production. Methods to compute the requirement of energy and labour for the production processes from raw material to the product at the farm gate are discussed. It is shown that limited amounts of added energy and labour are required to achieve the maximum possible production per hectare.

The form of the functions that relate the requirement for these resources with the level of production is considered in two limiting situations. These concern the minimum amount of added labour that is required when energy is abundantly available and the minimum amount of added energy that is required when labour is abundantly available. By means of these functions and the added energy and added labour used in the actual farm situation, iso-yield functions are constructed. These functions identify the possibilities for substitution of energy and labour during the production process at various yield levels.

The shape of the expansion paths indicate that there may be a considerable range of production situations where the yield per unit of added energy, the yield per unit of added labour and the yield per unit of surface increase with increasing use of added labour and energy per hectare, whereas the added energy use per unit of added labour decreases at the same time.

Some resulting options for growth, with special reference to the situation in the Netherlands, are discussed.

\section{Introduction}

Since it is assumed that the days of cheap energy are probably over, considerable attention has been paid to the role of energy in agricultural production. It has been realized that energy is not only used directly in the form of oil and electricity for propulsion and heating, but also indirectly for the manufacture of fertilizers and farm machinery and for reclamation and maintenance of the soil. Apart from that, the energy supplied through labour and the sun is also considered.

A recent number of SPAN (Vol. 18, No 1, 1975) is completely devoted to this 
problem of energy use in agriculture and through all the articles it appears that there is still considerable confusion with respect to the computation of the total energy use per unit of aricultural product, the meaning of the efficiency of energy use in terms of energy gained and in general with regard to arranging the information in proper perspective.

Surprisingly enough, it is not realized that similar calculations as for energy now, have been made for labour (see, for instance, Fourastié, 1965). Since it may be reasoned that labour and energy are the two basic resources, it seems worthwhile to combine these two approaches, placing special emphasis on the degree in which it is possible to replace the one by the other in agricultural production.

This article is a first attempt at such an approach and is especially speculative in its purpose to support the development of strategies of food production, adjusted to efficient use of labour, energy and the sun, which radiation is exploited. It is also highly rudimentary, because a quantitative analysis of experimental and statistical data is still lacking. The effort required for this was considered too large at a stage where the methodology is still underdeveloped.

At first the resources of agricultural production are considered, the special position of energy and labour being emphasized. Subsequently attention is paid to the proper definitions of added labour and added energy in its direct and indirect form. A further important aspect concerns the potential yield concept and the characterization of the input needs dependent on the yield level. The form of the relation between added energy and yield and added labour and yield are then considered in the situation where the other resource is freely accessible. The form of these functions determine to a large extent the shape of the iso-yield curves in diagrams with the added energy and added labour along the axes and these curves finally reveal the options for efficient use of labour and energy in various situations of availability.

\section{Labour and energy as basic resources}

Agriculture is the human activity that transforms solar energy at the earth's surface into useful (edible) chemical energy by means of plants and animals. The prime resource is labour, because it appears possible to grow crops without drawing upon any resource of energy and raw material not contained in the soil and the radiation from the sun. Yields are then often small and may be improved considerably by drawing upon outside resources of energy and matter. Like labour, energy is dissipated during its use and therefore a more basic resource than matter, which may be recycled. At least when viewed from a technical point of view; economically there is no reason to attribute any special role to energy in comparison to other resources that may be available in limited supply.

Indeed, the scarcity of all means of production may be measured by the amount of labour and energy that is needed for its production from the raw materials. According to this view, liquid and gaseous fossile fuel are not scarce at all, because the labour and energy required for its mining and transport are small. This lack of scarcity in the Netherlands is reflected by the low cost of natural gas. Its much 
higher price reflects the fact that gas, although easy to gain, is available in a limited amount and easily subjected to manipulation by those controlling the sources.

The amount of organic material available in fossile and not so fossile form equals 5 times the amount of oxygen in the air, and therefore it could be reasoned that the energy supply is inexhaustable for every practical purpose. However, the limit of supply is attained as soon as the energy required for mining and transport of the fuel is in excess of its energy content and this limit may be attained when about $5 \%$ of the oxygen of the air has been used. Phosphate is abundant so long as it is available in high concentrations at various suitable locations. It is anyhow unexhaustable because less and less concentrated supplies may be exploited at the expense of more and more energy and labour.

Although besides labour, energy is needed to organize the material world around us, it would not be necessary to emphasize its role, if it should appear that energy remains in abundant supply, due to the existence of nuclear or other sources. This position is taken by Fourastié (1965) who considers only the supply and use of human labour.

\section{Definitions and computational problems}

Thermodynamically, the energy content of a fuel should be characterized by its free energy content, that is the heat of combustion minus the work dissipated during expansion at normal pressure when used. Especially when such diverse sources of energy as oil, differences in height of water and nuclear devices are compared is it necessary to consider the free energy. But at the low level of sophistication of present computations, the heat of combustion of fossil fuel is in general used, multiplying the energy use in the form of electricity by 3 , under the assumption that all electricity is generated from fossil fuel.

The added energy of a product is the total amount of energy used for its production and the production of all inputs from the raw materials used, inclusive of the energy used for transportation. The added labour of a product is the total amount of labour used for its production and the production of all inputs from the raw materials used, inclusive of the labour used for transportation. These definitions are formulated as simple as possible and need therefore some further explanation.

Added energy and added labour of agricultural products are taken into account only during the uphill process from raw material to product at the farm gate and not during the downhill process from farm to consumer. The difference is important, because it is suggested that the added energy during the downhill process is several times larger than during the uphill process. This holds also for the added labour, as is reflected by the difference in price of a product at the farm gate and in the supermarket. The distinction between direct use of energy and labour on the farm and indirect use during manufacture and transport of all inputs used is also made, but the border between both is mobile.

Added energy and added labour dissipate during human consumption, so that the added energy and added labour cost of labour itself are zero. A possible ex- 
ception could be made for the cost of transport of labour between house and farm and for the energy and labour added during schooling. Education is considered a right of the individual in modern society, and therefore its cost in terms of added energy and added labour are not considered an investment which is to be accounted for during the manufacture of a product. In a slave society this would be different.

The added energy and added labour of keeping horses must also be taken into account. When horse food is bought, it is not the energy content of the food that matters, but the added energy and added labour that goes with the food. Homegrown food is part of the internal cycling and does not figure at all in the analyses of input and output. The added energy of a farm product that does not draw upon other inputs than labour is zero, irrespectively of horses, (home-made) windmills or other energy-consuming or energy-producing devices being used. This is because the energy from the sun, be it in the form of radiation, wind, or home-grown food for the horse, is the source which is exploited in farming and not used as a means of production. Obviously, there is an analogy here with the special position of soil as a capital good in economics.

The added energy and added labour of capital goods are passed on in accordance with the rate of depreciation, so that the end result of any computation depends on the state of technology and the economy and changes with time.

The added energy and added labour may be determined by analysing in detail the production process on the farm and of all production processes down to the raw material. Not only the added energy and added labour during the manufacture of a tractor is to be accounted for but also that of the steel required for the manufacture of the tractor and of the tractor factory. The number of processes to be considered during each step along the lines increases geometrically, but the contribution of each process decreases also rapidly. In processes which result in more than one end-product, there is no logical way to allocate the added energy and added labour to these products. The analogous problem in economy is often solved by partitioning the costs according to the relative prices of the products, which is in the final analysis an arbitrary decision. However, since the results of all computations are anyhow dependent on time and circumstances, this probably is the best procedure also here.

As has been suggested by Dekkers et al. (1974), the problem of energy accounting can also be approached by means of Leontief's input-output matrixes. If sufficiently 'homogenous' sections are considered, the input of energy and labour into one economic section may be allocated to other sections according to the money flow. Many sections have to be considered to achieve sufficient homogeneity within each section, so that the method requires also an exploding effort. A combination of both methods is most convenient. The results of an input-output analysis are then used as the inputs for a technical analysis of the production process under consideration, and so it suffices to analyse only a limited number of steps of the latter process.

Many calculations of added energy are done at present, without a proper analysis of the difficulties, or proper standardization of the methods and - what is even more disturbing - without considering at the same time the added labour and 
without using the experience in the field of labour accounting. The present author took part in the effort (Dekkers et al., 1974; de Wit, 1975) but looks very sceptical upon the results achieved up to now by himself and others, which is also one of the reasons why this article is concerned with the discussion of methods and principles and leaves number grinding for the time being alone.

\section{Production and input functions}

Energy and labour accounting may provide some insight in the existing situation but not in the possibility of substituting energy and labour by varying the input mix, needed to achieve a given yield. For this purpose a technical analysis of the options is necessary and this may be done along the lines suggested in this section.

A classical tool in crop husbandry research is the field experiment in which one or more growth factors are varied independently or in combination while the effect on yield is recorded. If any, this effect is in general characterized by production functions of diminishing returns, in which the rate of increase of the yield decreases with increasing yield, so that gradually an optimum is approached which value depends on the other growing conditions which are assumed not to vary between treatments. In this way, a first indication is obtained of the factors that may affect the yield, but it remains obscure how much the yield may be increased when all controllable growing conditions are chosen in the optimum range.

The knowledge of the physiology and ecology of the crop growth process has been increasing so much during the last 20 years that it is feasable to estimate such a potential. This opens the possibility to compare yields that are actually achieved with possible yields and to investigate reasons of discrepancy (de Wit, 1968, 1970, 1972).

At first the potential growth rate of a closed green crop surface optimally supplied with water and nutrients is calculated from relevant plant physiological and weather data. Subsequently, plant and varietal characteristics are considered that govern the development of the crop throughout the season with respect to time of flowering, time of ripening and the distribution of the organic material to the various organs. In this way, it has been estimated for the Netherlands that the potential production of wheat varieties with sufficient sink capacity in the ears, with sufficient strength to withstand lodging and with customary flowering and ripening time, is about $9500 \mathrm{~kg} / \mathrm{ha}$. This does not mean that higher yields can not be achieved, but this would require varieties that flower earlier, ripen later or have a better photosynthesis capacity than has been observed up till now.

Computed potential yields and actual yields are given in Fig. 1 (de Vos, IBS, pers. comm.) for a period of 5 years. The actual yields that are obtained by the farmer were about $5000 \mathrm{~kg} / \mathrm{ha}$, whereas the best varietal trials resulted in yields of a little over $7000 \mathrm{~kg} / \mathrm{ha}$. Although the usual inputs of water, fertilizers and so on were necessary to achieve medium yields, it was impossible to bridge the gap between actual and potential yields by further manipulation of these inputs. This gap could be bridged by maintaining a sufficiently healthy and green crop surface until seed ripening by controlling 'ripening diseases', as is shown by some experi- 


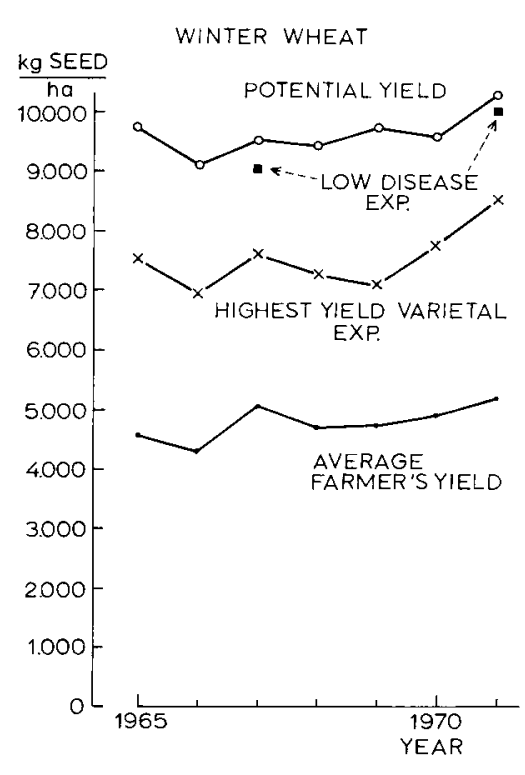

Fig. 1. Various yield levels in the Netherlands. (Personal communication, de Vos, IBS, Wageningen.)

mental results in the graph and confirmed by more recent research of de Vos and co-workers (IBS).

Since it is possible to attain potential yields with various crops, it has also been demonstrated that this may be achieved by manipulating a limited number of growth factors over a limited range or, in other words, by a distinctly limited effort.

Depending on the yield level which is aimed at, the various yield-affecting measures have to be applied selectively. This situation is schematically presented by the input functions in Fig. 2, where the yield goal is given as the independent variable along the horizontal axis and the need for various growth factors or crop husbandry

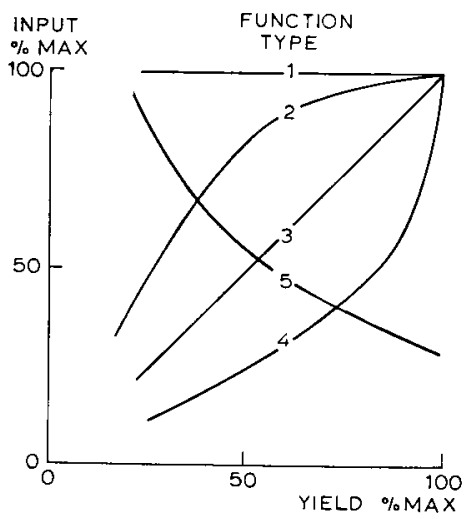

Fig. 2. Various types of input functions.

Neth. J. agric. Sci. 23 (1975, 
measures, along the vertical axis, all in percentages of their maximum. These input functions only characterize the needs for various inputs, which may be substituted to some extent with each other. For instance, deep ploughing may substitute to some extent fertilization and dense sowing may partly substitute active weed control. Therefore the functions should be vizualized as broad bands, rather than thin lines.

Input functions of type 1 present those factors and measures that are to be applied at about the same intensity, irrespective of the yield. Examples are the amount of seeds, of minor elements, the amount of ploughing and the spreading of fertilizers. And of course the main reclamation activities, like clearing, levelling, destoning, and so on.

The need for amelioration measures, such as the control of water and $\mathrm{pH}$, increases according to the input functions of type 2 . A pH which is good enough for a medium yield is good enough for a maximum yield, and the need for water and water control hardly increases when yields approach the maximum. The same holds for the need of phosphate since the uptake by the plant is often small compared with the continuous immobilization in the soil. Even the necessary amounts of nitrogen are represented by functions of type 2 rather than by those of type 3, because maximum yields are mainly achieved by avoiding diseases in the second half of the growing period when the plant has attained its final size and its main nitrogen requirements are already covered. Also pastures need relatively less nitrogen when yields are high, mainly because high and controlled growth rates combined with a proper harvesting regime necessitate and enable the application of the proper amounts at the proper time. The recovery of nitrogen may approach $100 \%$ (Alberda, 1972) instead of the almost unavoidable $50 \%$ at lower yield levels. To what extent high yields are again wasted during their further processing by means of animals is another matter.

Type 3 functions hold obviously for the amount of handling that is necessary after harvesting, but examples for inputs during the actual growth process could not be visualized. Input functions of type 4 characterize the control of many diseases with an epidemic nature, because dense crops provide often a good environment for their development, and lengthening of the actual growing period during ripening gives the epidemy the time to reach economic damage levels. Within the higher yield range, there also may be more need of the use of chemical growth regulators. The use of varieties that are adapted to local conditions and have a broader resistance spectrum against lodging and diseases increases also progressively with increasing yields.

Type 5 functions also exist. They present the intensity of weed control, which is easier the better the growth of the crop and a nuisance throughout the season when yields are low. In many situations, these curves present also the need for special methods of erosion control, which is often difficult when yields and therefore the production of roots, stubbles and mulching material is low.

The input functions in Fig. 2 only characterize the various inputs, which may be substituted to some extent for each other. Hence, there is a wide spectrum of input mixtures that enable the realization of each yield level, even the maximum, which 


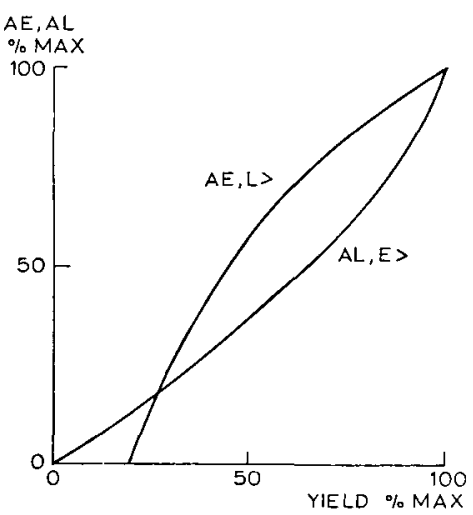

Fig. 3. $\mathrm{AE}_{\mathrm{L}}>$ : The minimum amount of added energy that is required for a given yield, when labour is abundantly available.

$\mathrm{AL}_{\mathrm{E}}>$ : The minimum amount of added labour that is required for a given yield, when energy is abundantly available.

All quantities are expressed in percentages of the maximum.

may of course vary with crop species, soil and climate and of which only a part is feasable from an economical, social or environmental point of view. Therefore, an identifiable problem exists only after introducing an ordening principle that governs further analyses. For this purpose two extreme situations will be treated. These are the minimum amount of added labour that is necessary when energy is abundantly available and the minimum amount of added energy that is necessary when labour is abundantly available. It is necessary for this to resolve each input in an added labour and added energy component, and to select the manufacture process of the inputs that achieve the desired results with either the least amount of added labour or the least amount of added energy.

The two input functions that are needed are schematically presented in Fig. 3. It is remarked that there is no reason to assume that both functions are straight lines through the $(0,0)$ and $(100,100)$ point or are in some other way the same and that at least their shape in qualitative terms may be found by reasoning.

The input function for added energy with unlimited access to added labour will be considered first. This curve does not pass through the origin, because it is possible to achieve some yield with the input of labour only. In general, the yield level without the input of added energy is about $10 \%$ of the potential yield or about $1000 \mathrm{~kg} / \mathrm{ha}$ in terms of wheat, but on good soils in the Netherlands this yield level is about $20 \%$ of the potential. This figure is derived from an analysis of historical data (Baars, 1973), but cannot be verified because many soils in the Netherlands have been heavily fertilized with energy-rich phosphates.

Whatever the input of labour, higher yields cannot be achieved because the fertility of the soil can be improved only by the use of outside resources in the form of fertilizers and sometimes heavy machinery for ameloration. These inputs are particularly rich in added energy and their use is characterized by input functions of type 2. However, to increase the yield level from median yields onwards, inputs that are characterized by type 4 functions are relatively more useful. These are manufactured and applied with relatively low use of energy. Therefore the input function of the required added energy with unlimited acces to labour is at first steep and levels off towards the end. 
The function for required added labour with free access to energy differs in various aspects of the former. Obviously, it is impossible to achieve any yield without the use of labour, so that the function passes through the origin. On the other hand, is is possible to mechanize and automatize to a large extent at relatively low yield levels that must be anyhow achieved by means of energy-rich inputs, like fertilizers. And this is possible with relatively low use of labour. However, the necessary inputs at higher yields are characterized by functions of type 4 , and the development and use of these inputs require a relatively greater use of labour. Therefore the input function of the needed amount of labour with free access to energy steepens with increasing yields.

The form of these input functions depend on the crop, the production conditions and the technological know-how. The curves do not depend on the economic situation because they characterize a limiting situation in the technical sense. A detailed quantitative analysis of even some situations requires considerable intellectual and experimental effort, which is only justified when the need for such an analysis is thoroughly established. Whatever the outcome, it is claimed here that the basic production relations are sufficiently established to state that any reasoning leading to the suggestion that the input functions are curved in the other direction as depicted in Fig. 3, contains arguments that can be proven to be false.

\section{Iso-yield diagrams}

The above analysis shows to what extent energy and labour cannot be substituted for each other in the extreme situation. However, agriculture is practiced in situations where both have their price, so that more is used of each than would be needed when the other were freely accessable. These above minimal amounts are substitutable with unit elasticity. This means in its most simple form that $d \ln \left(\mathrm{AE}-\mathrm{AE}_{\mathrm{L}_{>}}\right) / d \ln \left(\mathrm{AL}-\mathrm{AL}_{>}\right)$equals -1, (Allen, 1968), so that the iso-yield function is given by:

$$
\left(\mathrm{AE}-\mathrm{AE}_{\mathrm{L}_{>}}\right)\left(\mathrm{AL}-\mathrm{AL}_{\mathrm{E}_{>}}\right)=\mathrm{C}=\text { constant }
$$

This function relates the added energy and labour at a given yield level and should not be mistaken for a production function of the form: Production $=f(A E, A L)$. $\mathrm{AE}$ and $\mathrm{AL}$ present all combinations of added energy and added labour that are at least required to obtain a given yield, and $\mathrm{AE}_{\mathrm{L}}>$ and $\mathrm{AL}_{\mathrm{E}}>$ are the minimum needed amounts of added energy and labour when the other is freely accessible. Both constants define the minimum necessary amounts to achieve the yield concerned, and are, as illustrated in Fig. 3, very much yield-dependent. On the other hand, it is suggested that the third variable $\mathrm{C}$ which governs the curvature of the hyperbolic function is practically a constant function of the yield, since the technical arsenal that is necessary to substitute energy and labour is similar at any yield level. This may be a too rigourous schematization, like the assumption of symmetry implied by the absence of power terms in Eq. 1.

Examples of iso-yield functions, i.e. curves of equal yields in dependence of added energy and labour, are given in the diagram of Fig. 4 for a 20, 50 and $100 \%$ 


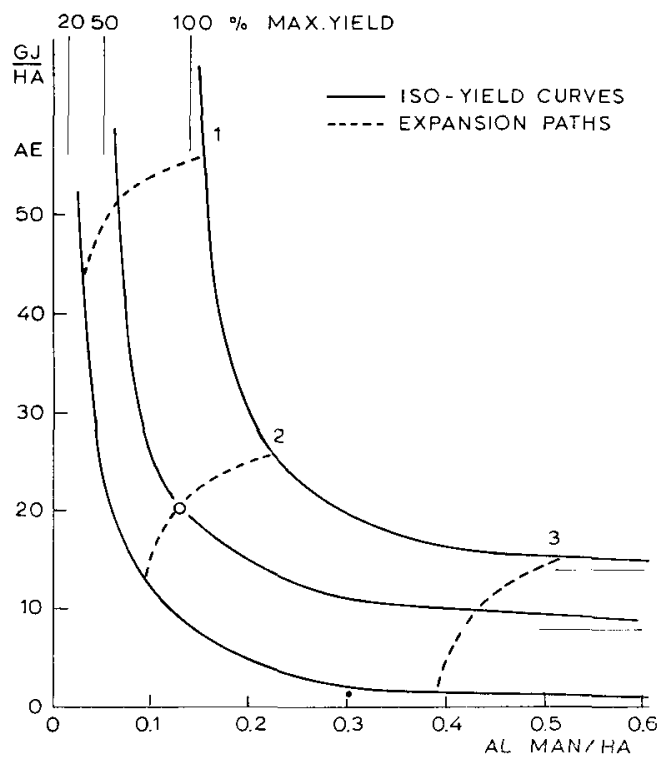

Fig. 4. Iso-yield functions of added energy versus added labour for the 20,50 and $100 \%$ yield level. The curves are assumed to hold for farms in the south-western clay district in the Netherlands, around 1965.

yield level. This diagram vizualizes the common notion that it is easy to replace relative large amounts of energy by relatively small amounts of labour when much is used of the first, and that the reverse is true when much is used of the latter. On the other hand, it should be noted that a proportionate increase of added energy and added labour does not necessarily lead to a less than proportionate increase in yield. This common notion of diminishing returns is not reflected because the input mixture may vary at the same $\mathrm{AE} / \mathrm{AL}$ ratio.

The axes of the diagram are scaled to give some idea of the quantities involved and of the difficulties that are encountered. The actual values should not be taken very seriously.

The open circle in Fig. 4 presents the added energy and added labour per hectare on a farm in the middle of the 1960's in the south-western clay district in the Netherlands. The added energy figures are obtained from Dekkers et al. (1974) with this difference that human labour is not considered as a source of energy and that the energy use through fertilizers is adjusted upwards on basis or more conclusive information (Schuffelen, 1975). The added energy appears to be about 20 gigajoules (GJ) per hectare, which is equivalent to the heat of combustion of about $1250 \mathrm{~kg}$ of organic matter. This is roughly in agreement with the often cited figure of Pimentel et al. (1973), that in arable farming about three times more energy is produced in edible form than used in the form of fossile fuel. Since potential yields of organic matter are about $20000 \mathrm{~kg} / \mathrm{ha}$, this illustrates that the energy needs on a farm are relatively low. However, it should be realized that the technology to convert organic material into energy that can be used to manufacture the inputs needed for production is not available and may be expensive to develop and to use. 
The labour employed on the farm amounted to $0.065 \mathrm{man} / \mathrm{ha}$, but this direct use should be increased with the indirect labour, used for the manufacture of all inputs. Since the factor costs (labour, rent of capital) and the non-factor costs (products and services used) are about the same, it is assumed that the indirect labour use is the same as the direct labour use, so that the added labour amounts to roughly $0.13 \mathrm{man} / \mathrm{ha}$. Dovring (1967) estimated by means of better, but still short cutting procedures that the indirect (off-farm) labour cost were $50 \%$ of the direct (on-farm) labour cost in the USA in 1960.

The actual and potential yield data indicate that the yield level on this farm was about $50 \%$ of the maximum, so that the $50 \%$ iso-yield curve may pass this point. Even this is an assumption, because it is now known to what extent the production was rational, i.e. occurred with the least amount of added energy and labour at the calculated $\mathrm{AE} / \mathrm{AL}$ ratio.

A further analysis of the input data shows that a little over half of the energy was used for mechanized operations, like ploughing, sowing, harvesting, weed control and so on. In principle, these operations may be done in hand labour. On the other hand, somewhat less than half of the added energy was used for fertilizer and other yield increasing inputs and this means that the horizontal asymptote of the $50 \%$ iso-yield function is positioned around the $8 \mathrm{GJ} /$ ha level.

Nobody has actually tried to mechanize and automatize as much as possible so that the position of the vertical asymptote is rather obscure. This asymptote is drawn under the assumption that the labour needs could have been reduced towards half in 1965, taking into account that a too great reduction at the farm level is balanced by an increased need for labour during manufacture and maintenance of the highly automated machinery. The other iso-yield lines are drawn under the assumption that the functions of Fig. 3 hold and that the value of the constant $C$ in Eq. 1 is indeed independent of the yield level.

The marginal substitution ratio or the slope of the iso-yield function is:

$$
\frac{\mathrm{AE}}{\mathrm{AL}}=\frac{\mathrm{AE}-\mathrm{AE}_{\mathrm{L}} \geq}{\mathrm{AL}-\overline{A L}_{\mathrm{E}_{>}}}
$$

For the farm situation in 1965 (at the open circle) its value is $190 \mathrm{GJ} / \mathrm{man}$, which means that the energy flow should increase with $190 \mathrm{GJ} /$ year to achieve the same production with one man less. This amounts to an energy-flow of $6 \mathrm{~kW}$, and that is not contradictory to the $5 \mathrm{~kW}$ that is said to be necessary to substitute a labour place in industry without decreasing production.

It is worthwhile to consider the position of the point that characterizes agriculture around 1800 in the south-western clay district in the Netherlands (Baars, 1973; Dekkers et al., 1974). The yield at that time was about $2000 \mathrm{~kg} / \mathrm{ha}$ in terms of grain and $4000 \mathrm{~kg} / \mathrm{ha}$ in terms of total organic matter, or $20 \%$ of the potential. This yield was achieved without the input of fertilizers and with a direct labour input of 10 men on a 50 ha farm. Taking the somewhat longer working time and a little labour of craftsmen into account, this amounts to an added labour of about $0.3 \mathrm{man} / \mathrm{ha}$.

The yield of close to 25 ha was used to support some cows, eight full-grown 
horses and young animals in total amounting to about 26 'standard cows'. These animals produced $8500 \mathrm{~kg}$ milk per year and less than $10000 \mathrm{~kg}$ of animal for slaughter, the greater part as horse meat. This indicates that animals were mainly used for work and for concentrating minerals in the form of manure.

An organic matter consumption of half of the total dry matter yield of $4000 \mathrm{~kg} /$ ha is equivalent to an energy consumption of roughly $30 \mathrm{GJ} / \mathrm{ha}$, which is considerably higher than the present added energy use of $20 \mathrm{GJ} / \mathrm{ha}$. However, taking digestion losses, maintenance and replacement cost into account, the efficiency of animals as a source of mechanical power is only a few percent of the energy consumed as organic material.

Hence, recalculated in terms of fossile fuel used in modern equipment, this total is equivalent to only a few $\mathrm{GJ} / \mathrm{ha}$, a low figure that could have been derived directly from the well-known fact that the power of a horse is less than one horse power. This recalculation situates the point for the $1800 \mathrm{farm}$ in the 1965 diagram close to the horizontal axis at $0.3 \mathrm{man} / \mathrm{ha}$ and also close to the $20 \%$ iso-yield function.

The estimates in this section are for a farm in the south-western clay district around 1965. The iso-yield functions are different for other farms, for other regions and for other times. However, it seems safe to assume that the form and the relative position of the iso-yield functions is approximate the same in various situations because they depend on basic principles. Subsequent generalisations are based on this assumption and do not imply that aggregate iso-yield functions for a country as a whole are meaningful.

\section{Historical growth curves}

Since many years, the price of labour has been increasing continuously with respect to the price of energy, and as far as agriculture is concerned, the product prices have been maintained at such a level that the income for the farmers is almost maintained at parity with the income of other sections. Whatever the exact mechanism, this had led to a development where the added labour use per hectare has been decreasing and the added energy use and the yield per hectare has been increasing at the same time. Such a growth course may be depicted in an added energy versus added labour diagram, as has been schematically done in Fig. 5. In interpreting such curves it should be realized, however, that in the course of time not only the technological arsenal changed to adapt to the changing economic situations but that also the technological know-how increased.

This means that the iso-yield functions shifted in the course of time more and more towards the origin of the graph. Indeed, the increase of technological knowhow is characterized by the decrease of required added labour and added energy at a given ratio of added energy and added labour and at a given yield level. This definition is vizualized in Fig. 5 by the distance between the iso-yield functions along the line through the origin.

Since in the course of time the ratio between added energy and labour changes also, it is impossible to determine this increase of technological know-how by means of a statistical analysis of data collected in the actual farm situation. How- 


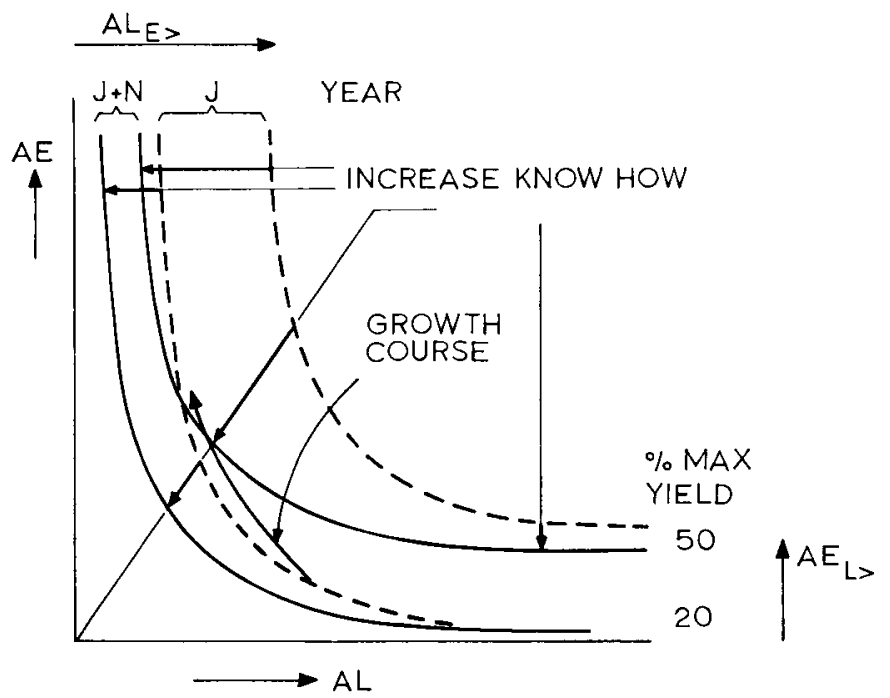

Fig. 5. A schematic presentation of the influence of increased know-how on the position of the iso-yield functions and a suggested form of a historical growth course.

ever, the required added energy or added labour to attain a given yield level in the limiting situations (i.e. $\mathrm{AE}_{\mathrm{L}>}$ and $\mathrm{AL}_{\mathrm{E}>}$ ) are not confounded by economic constraints, and it is at least in principle possible to reconstruct their decrease in the course of time by a technical analysis of possibilities. This has not been attempted as yet.

The kind of increase in technological know-how is dictated by economic needs, and it is assumed that the relative decrease in the value of $A L_{F_{1}}>$ has been much more pronounced than the relative decrease in $\mathrm{AE}_{\mathrm{L}>}$, simply because in Western society labour has been in short and energy in abundant supply. This assumption is reflected in Fig. 5, where the values of $A L_{>E}$ are reduced relatively more than $\mathrm{AE}_{\mathrm{L}>}$.

\section{Expansion paths}

The development in the future may not be governed so much by relatively decreasing energy prices, but by a constancy of the price ratio of energy and labour at a considerably higher level than the present. Be it only because the suppliers of energy are determined to put their monopoly position to good use and to keep up with inflation. Neglecting many complications, it could then be assumed that the situation will be more effectively governed by the marginal substitution value of both resources, or settle at a point of an iso-yield function where it is neither advantageous to replace energy by labour nor labour by energy. In mathematical terms, this marginal substitution ratio or slope of the iso-yield function equals

$$
(d \mathrm{AE} / d \mathrm{AL})_{\mathrm{M}}=\mathrm{PL} / \mathrm{PE}
$$


where PE and PL are the prices of energy and labour. Barring time lags due to price changes, inertia of capital goods and assuming a competitive economy, all activities being on the farm or otherwise should then be guided towards this marginal substitution ratio by the invisible hand of Adam Smith.

Each iso-yield curve has its marginal slope and the curve that joins these slopes is called in econometry the expansion path. Three of these paths are given in Fig. 4, which hold in accordance with their number 1,2 or 3 for a situation where the energy price level is low, medium or high, respectively, compared with labour. Clearly, the expansion paths are not straight lines through the origin so that the optimal ratio of added energy and added labour (AE/AL) varies with the yield level in spite of the constancy of the marginal substitution ratio. Some consequences of this will be discussed in the next section.

Along the expansion path, the total costs of energy and labour may be calculated according to

$$
\mathrm{TC}=\mathrm{PE} \cdot \mathrm{AE}+\mathrm{PL} \cdot \mathrm{AL}
$$

for each yield level and in this way a curve may be constructed that relates these cost of production with the yield (van Riemsdijk, 1960). Given the price of the product, the yield level may then be found that, with respect to energy and labour, leads to the highest profit along the whole line of production from raw material to end product. Of course, the price of agricultural products may be comparatively so low that any production leads to losses. On the other hand the price may be so high that it is advantageous to produce at the potential rate.

Each entrepreneur along the line tries continuously to maximalize his profit on the basis of current prices of goods, capital and labour, and monopolists and pressure groups alike try to maximalize their profits by manipulation. Moreover, all energy and labour is not equally expensive for various production processes, and means of production may be imported from countries where the marginal substitution ratio of both has another value. For a further analysis it seems therefore useful to abstract as much as possible from behavioural aspects governed by prices, which means that some other principles of governing behaviour have to be considered. In the further analyses, it is therefore assumed that shortage of energy may become so overruling that governments will at least attempt to direct future growth by aiming at a marginal substitution ratio of energy and labour which is considered optimal and maintainable for society as a whole. It is also assumed that attempts will be made to regulate agricultural production through prices and other ways to some optimal pattern in terms of use of energy, labour and land.

\section{Options for growth}

Agriculture serves many purposes in the Netherlands. Before the war its function as a source of employment, during the war its function as a source of food, and after the war its function as a source of income was emphasized, and during recent years agriculture is recognized also as a source of landscapes and one of the many sinks of fossil fuel. 
But what about future? Agriculture should remain sufficiently productive to function as a source of income for farmers and agriculturally based industries, both uphill towards the farm and downhill towards the consumer, but also guarantee a reasonable diet for the population in times of international stress. At the same time agriculture should remain a source of employment, contribute its share towards a more efficient energy use, function as a source of land for urban development and semi-natural conservancies, rehabilitate valuable landscapes and in general lessen its effect on the environment.

There is considerable pessimism as to whether agriculture will be able to satisfy all these demands, and this is justified in so far that it will be difficult, but not a priori unfeasible. And since there will be enough pessimism until the year 2000, a more optimistic scenario may restore the balance somewhat.

The food consumed in the Netherlands in terms of calories consists for about one third of animal products and in terms of proteins even for two-thirds. In spite of this and the large population density of over 500 capita per $\mathrm{km}^{2}$ cultivated land, the country is self-supporting in so far as food is concerned (Dekkers et al., 1974). This high productivity forms the necessary basis for a healthy 'agri-business' which contributes further through the import of plant products and the export of animal products substantially towards the trade balance of the country. In view of the still increasing population, this favourable situation with respect to self sufficiency and economy can only be maintained if the productivity of of agriculture is to increase for some time to come, although not necessarily at the rapid rate of the last decades. Since it is well established that the yields per hectare may be at least $30 \%$ higher, this would be technically feasible, even when other claims on the soil have to be satisfied. Of course it is always advantageous to achieve this by increasing the technological know-how, so that at the same $\mathrm{AE} / \mathrm{AL}$ ratio less of both are required to achieve the same yield.

At the same time, however, government policy could be directed towards a decrease of energy use per unit of product and per unit of man by promoting other production patterns to save both energy and the environment. If it is assumed that most agricultural enterprises in the Netherlands are somewhere along an expansion path situated between patch 1 and 2 in Fig. 4, the three requirements of increased yields per hectare, and decreased energy use per man and per unit of product could be satisfied at the same time. This course should lead to the use of more added labour per hectare which would be undesirable when at the same time the production per man should decrease considerably; however this depends on the situation. In the condition of expansion path 1 the added labour per hectare would increase more than two-fold with an increase in yield from the 50 to $100 \%$ level. But in the case of expansion path 2 , the added amount of labour would increase less than two-fold with a two-fold increase in production. And this opens the possibility of increasing the volume production per hectare, per unit of added energy and per unit of added labour, whereas the use of added energy per unit of added labour would decrease and agriculture would remain a good source for skilled employment, at the same time. This is indeed the famous sheep with five legs that is needed so badly. 
Apart from the relatively low energy cost, several reasons may be given why such an obvious favourable production situation is not achieved at present. In the past, the farmer has been operating mainly at lower yield levels, roughly below $50 \%$ of the maximum, where it was necessary to increase the energy use per unit of labour to increase production. The diffusion of technological know-how is also a slow process. Moreover, there may be situations for which the differences between both curves in Fig. 3 are exaggerated. Then, the region of mutual benefit of energy and labour would be smaller. On the other hand there may be also situations where the reverse is true. However inaccurate the basic information, the wisdom of a policy which leads to the employment of only a few percent of the working population in agriculture and its supporting activities may be questioned.

The investment of added labour and added energy required to achieve high maximum yields could very well be too high on part of the soils, especially in regions where it would be anyhow worthwhile to conserve and rehabilitate landscapes, moulded by old agriculture practices. Since it is unnecessary for some time to come to use all the soils at maximum capacity, it would be a pity to spoil these, just before the days of cheap energy are over.

Environmentalists often assume that conservation and rehabilitation should be achieved by prescribing the agricultural practices that were formative in the past, which would imply the introduction of labour-intensive, energy-extensive and lowyielding agriculture. These methods would require large operating and income subsidies per hectare, but also condemn the farmer to operate at a substitution ratio of energy and labour which is not at parity at all with the marginal substitution ratio at which other farmers and society at large are allowed to adjust. But this implies working methods that are socially unacceptable and invite the clandestine use of more remunerative agricultural methods that approach the otherwise accepted substitution ratio.

Instead of describing historical farming methods it is necessary to develop goals for landscape parks, so that socially acceptable management methods with a normal substitution of energy and labour ratio can be developed, which leave the farmer as much freedom as possible to minimize his losses. If this appears impossible, so called landscape parks will be left alone as being socially unacceptable in terms of working methods, financially unacceptable in terms of income subsidies and practically impossible to enforce.

Options for different growth patterns exist in agriculture when a reasonable rate of energy consumption can be maintained. This may be the case in rich countries, but the situation is completely different for poor nations. Agriculture is executed there with a minimum of added energy. In this way hunger may be avoided in spite of a growing population so long as land is available that may be reclaimed with little organized effort. Such land is practically exhausted in various regions (Buringh et al., 1975, and unpublished analyses), and here further increase in food production is only possible by using outside energy resources - sometimes for large scale reclamation, but in most cases for fertilizers and other means of production. 
Growth courses as in Fig. 5, that have been followed by rich countries, require large amounts of cheap energy, which is then partly used to reduce the requirement of labour. Growth, if any, is more likely to take place along the expansion path 3 in Fig. 4, because energy will remain for a long time expensive with respect to labour in the poor countries of the world. This path of increasing yields is characterized by the use of more energy per hectare, more added energy per unit labour and more added labour per hectare. The latter is required because energy-rich inputs contain added labour and because higher yields means a larger need for labour on the farm when the use of energy-consuming machinery is avoided. However, this only path of growth is also thoroughly blocked by the old and the new rich who 'like the Dutch, are paying too little and asking too much'. Indeed, the price that the poor have to pay for energy-rich inputs is too large with respect to the price that they are able to make for their agricultural products. On the other hand, it should be realized that Western technology has been geared mainly towards labour-saving methods and that the art of growing crops with a minimum of added energy is hardly developed.

A rough analysis of Fig. 4 shows that also in the region of expansion path 3, the increase in yield in energy terms $(1250 \mathrm{~kg}$ organic dry matter $\equiv 20 \mathrm{GJ})$ is much larger than the energy needs to achieve this increase. However, the technological potential for the development of decentralized production methods of the needed energy-rich inputs like fertilizers by means of locally produced organic material is not only lacking, but may be a pie in the sky.

\section{Acknowledgments}

The advice of several agronomists, ecologists, economists and engineers during the conception of this paper is gratefully acknowledged. However, the advice is not always followed, because this speculative article would not have been completed in that case.

Factual information which is presented without proper reference was obtained by reading many of the internal reports that have been proliferating since the socalled energy crisis. Especially the reports prepared on behalf of the Steering Committee on Energy Research of the Goverment of the Netherlands (LSEO) are acknowledged.

\section{References}

Alberda, Th., 1972. Nitrogen fertilization of grassland and quality of surface water. Stikstof: Dutch nitrogen. Fert. Rev. 15: 45-51.

Allen, R. G. D., 1968. Macro-economic theory. McMillan, London, 420 pp.

Baars, C., 1973. De geschiedenis van de landbouw in de Beyerlanden. Pudoc, Wageningen.

Buringh, P., H. D. J. van Heemst \& G. J. Staringh, 1975: Computation of the absolute maximum food production of the world. Department of Tropical Soil Science, Agricultural University, Wageningen.

Dekkers, W. A., J. M. Lange \& C. T. de Wit, 1974. Energy production and use in Dutch agriculture. Neth. J. agric. Sci. 22: 107-118 
Dovring, F., 1967. Productivity of labour in agricultural production. Bull. Agric. Stn Univ. Ill. $726 ; 73$ pp.

Fourastié, J., 1965. Le grand espoir du XXe siecle. Presse de l'Université de France, Paris. (Dutch translation: Aula pockets 198, 1965.)

Pimentel, D., L. E. Hurd, A. C. Bellotti, M. J. Forster, I. N. Oka, O. D. Sholes \& R. J. Whitman, 1973. Food production and the energy crisis. Science 182, 443-449.

Schuffelen, A. C., 1975. Energy balance and the use of fertilizers. SPAN 18: 18-20.

Wit, C. T. de, 1968. Plant production. Symposium 'Agriculture and the world food supply'. Misc. Pap. Agric. Univ. Wageningen 3: 25-50.

Wit, C. T. de, R. Brouwer \& F. W. T. Penning de Vries, 1970. The simulation of photosynthesis systems. Proc. IBP/PP technical meeting on the prediction and measurement of photosynthetic productivity. Pudoc, Wageningen, pp. 47-70.

Wit, C. T. de, 1972. Food production: past, present and future. Stikstof: Dutch nitrogen. Fert. Rev. 15: 68-80.

Wit, C. T. de, 1975. Agricultural's uncertain claim on the world energy resources. SPAN 18: $2-4$. 